\title{
SOME SECULAR VARIATION EXPRESSIONS OF THE MAGNETIC DECLINATION.'
}

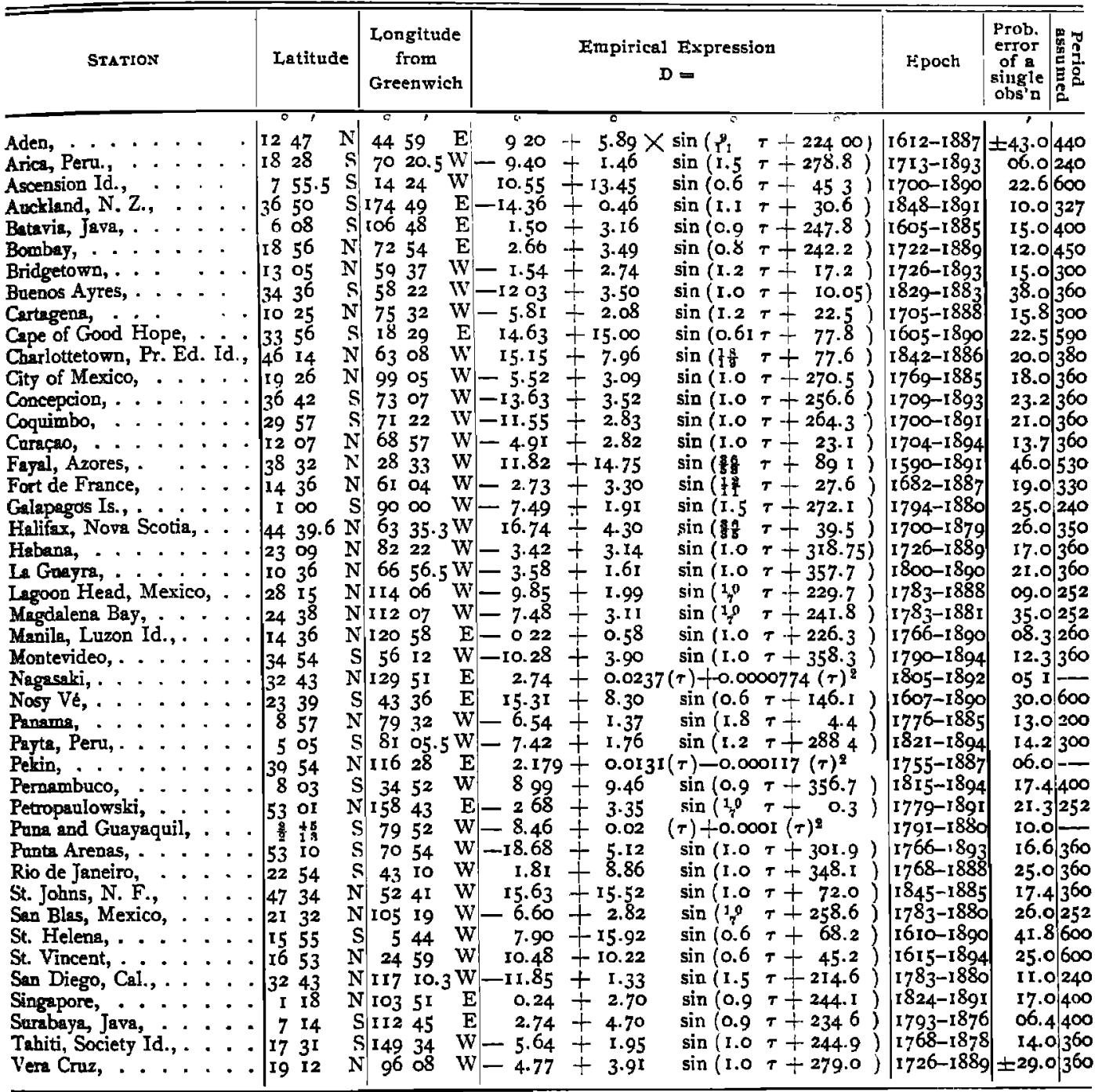

$$
\text { Washington, D. C. }
$$

G. W. LITTLEHALES.

I For details, I beg to refer to the Hydrographic Offce Publication, No. 109a, Conlributions to Terrestrial Magnetism, the Variation of the Compass. West declination is plus; east declination, min $u s$; $\tau$ stands for date-l 850 . Special care has been taken in the preparation of the above table. Where discrepancies occur between the data contained therein and those on pages 50 and 52, "Publication roga," the data given here should be taken. The expression for Bahia, Brazil, it was thought better to omit. 